\title{
Millennials: El nuevo reto del Marketing
}

Por Cecilia Rivera

Ingeniero y Master en Mercadeo con certificación en Inteligencia de Mercado, Catedrática de la Universidad Centroamericana José Simeón Cañas

Investigacion realizada por. Ingrid Berenica Canacas, Delmy Elena Jovel, Jacqueline Andrea Romero

uchos profesionales piensan que pueden mercadear al grupo de los Millennials por el simple hecho que alguna vez fueron jóvenes y por lo tanto los conocen. Esta aseveración está muy lejos de la realidad, considerando que vivimos en la era digital y que las generaciones pasadas que son los llamados generación " $X$ " y los Baby boomers no poseían smartphones y por tanto, no existía la maravillosa conectividad en que se vive hoy en día.

La pregunta para todo mercadólogo debería ser la siguiente: ¿Quiénes son este grupo peculiar de los Millennials? y ¿por qué es importante su estudio?

De acuerdo a (Forbs, 2016) la Generación "Y", conocida como la Generación del milenio o Millennials, comprende a los nacidos entre 1980 y 1995, jóvenes entre las edades de 20 a 35 años, que crecieron junto a los avances tecnológicos, incluyendo el del Internet, es decir la era digital. Actualmente en Latinoamérica un $30 \%$ de la población es Millennial. Esta generación se caracteriza por su apego a la tecnología, conviven e interactúan la mayor parte del tiempo en internet, realizan consultas, se informan a través de sus smartphones, tablets o computadoras, utilizan redes sociales como Facebook, Twitter, Instagram, Snapchat para comunicarse, expresar sus emociones y opiniones, comparten imágenes de sus actividades diarias. Todo instantáneamente, la mayoría se mantiene conectado todo el día ya que la tecnología está íntimamente ligada a su estilo de vida.

Según una proyección de la consultora Deloitte, en 2025, los Millennials representarán el $75 \%$ de la fuerza laboral del mundo (Forbs, 2016). La influencia de la tecnología, en esta generación en particular, es una característica que los diferencia radicalmente de las generaciones anteriores, junto con la necesidad de estar en constante comunicación, compartiendo actividades y emociones. Su estilo de vida ha influenciado no solo en las estrategias de mercadeo de las marcas que los quieren conquistar, sino también en el estilo de las organizaciones y el mundo laboral.

Su importancia radica en que son una generación que representa un cambio radical en la forma de comunicarse, expresar sentimientos y deseos e interactuar con los demás a tal grado que las organizaciones se han visto en la necesidad de modificar estrategias, procesos, productos y servicios para lograr captar su atención y motivarlos.

Unos 20 años atrás, nos enfrentábamos a un consumidor pasivo, muy difícilmente participaba del diseño de un producto y de un servicio y muy rara vez se tomaba en cuenta su opinión para generar mejoras o modificaciones. En la actualidad, debido en parte a las redes sociales y el internet, los consumidores son más activos en la creación de nuevos productos, les encanta la participación y la interacción con las marcas y frecuentemente las empresas consultan a los consumidores, entre los cuales los Millennials se destacan por su afinidad a la interacción vía red social.

Una diferencia muy significativa entre Millennials y las generaciones anteriores, es que para ellos es importante la conectividad mediante redes sociales y aplicaciones y se sienten aceptados cuando sus amigos le dan "Me gusta" a sus Post y les mandan emoticons en sus mensajes.

No queriendo ser consumidores pasivos por más tiempo, esta generación quiere participar activamente, co-crear, y, lo más importante, ser parte de las marcas que aman. A menudo, el proceso de co-creación comienza con el diseño del producto o servicio, incluye el viaje del cliente o la experiencia de compra y se ve más fácilmente en el marketing y medios sociales más cerca del final del ciclo de comercialización. De hecho, se podría argumentar que los beneficios funcionales y emocionales por sí solo no será suficiente para la marca para prosperar con esta generación, ya que los fanáticos de los Millennial sienten que tienen un interés compartido en el éxito de la marca (Jeff, 2013).

Debido a este deseo de participación, se generan muchas oportunidades para las empresas que quieran conquistarlos siendo necesario obtener un conocimiento más profundo acerca de los millennials sus intereses, necesidades y hábitos de consumo con el fin de desarrollar estrategias mercadológicas que los impacten.

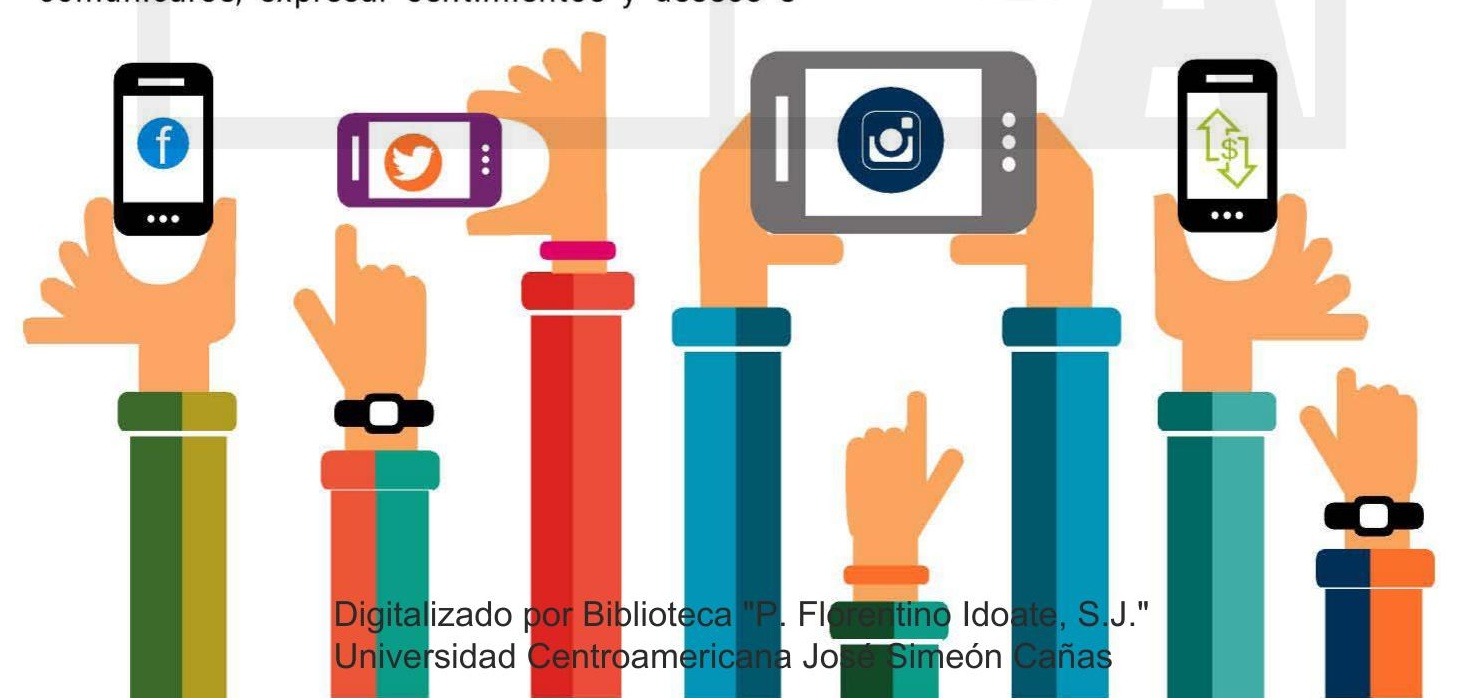


En El Salvador, no existen muchos estudios acerca de los Millennials, y al igual que las empresas para las universidades se ha convertido en un tema de investigación por esta razón la Universidad Centroamericana José Simeón Cañas (UCA), a través del Departamento de Administración de Empresas dirigió un trabajo de graduación para optar al grado de Licenciatura en Mercadeo denominado: "Estudio sobre los intereses, necesidades y hábitos de consumo de los Millennials Salvadoreños".

\section{Metodología}

Se desarrolló una investigación cuantitativa utilizando como instrumento de recolección de datos la encuesta. Se llevó a cabo en los meses de mayo y junio del 2016 en la ciudad de San Salvador y ciudades aledañas.

Se entrevistaron a 400 jóvenes nacidos entre los años 1981 y 1995, entre los 20 y 35 años, utilizando un margen de error de 5\%; residentes del área metropolitana de San Salvador y ciudades aledañas. A la vez se realizó un focus group o grupo focal en la UCA con el mismo perfil de participantes.

El objetivo principal de la investigación era recopilar información que permitiera la identificación del perfil del Millennials Salvadoreño, para conocer necesidades, intereses, motivaciones, hábitos de consumo y la influencia en su comportamiento (Canacas, Jovel Rodriguez, \& Romero Vanegas, 2016)

\section{Resultados}

Existen factores del entorno que influyen en el desarrollo de los jóvenes Millennials salvadoreños, entre estos se puede mencionar, los políticos, económicos, tecnológicos, educativos y recreativos, de los cuales depende las oportunidades que se les puedan presentar. Puesto que, esta generación se encuentra en edad suficiente para entrar al ámbito laboral, donde se juegan puestos de trabajos y son los más preparados y con mayor experiencia quienes pueden obtener dichas plazas. A consecuencia de los factores mencionados anteriormente, surgen otros factores como la migración y la violencia, que impulsan a los jóvenes a migrar a países en busca de seguridad y mejores oportunidades, la mayoría arriesgando su vida, viajando de manera ilegal, a pensar de las circunstancias que se viven en el país, estos jóvenes aún tienen valores, que son inculcados desde sus hogares, tales como la religión, el amor a la familia y el respeto hacia el medio ambiente. (Canacas, Jovel Rodriguez, \& Romero Vanegas, 2016) Conectividad

Cuando se entra en el estudio de la conectividad se les preguntó: ¿Qué grado de importancia resulta para usted tener acceso a tecnología para poder realizar actividades diarias? Es interesante ver como los Millennials le conceden una gran importancia a la tecnología; prácticamente forma parte de su vida.

\section{Importancia en tener acceso a tecnología para realizar actividades diarias}

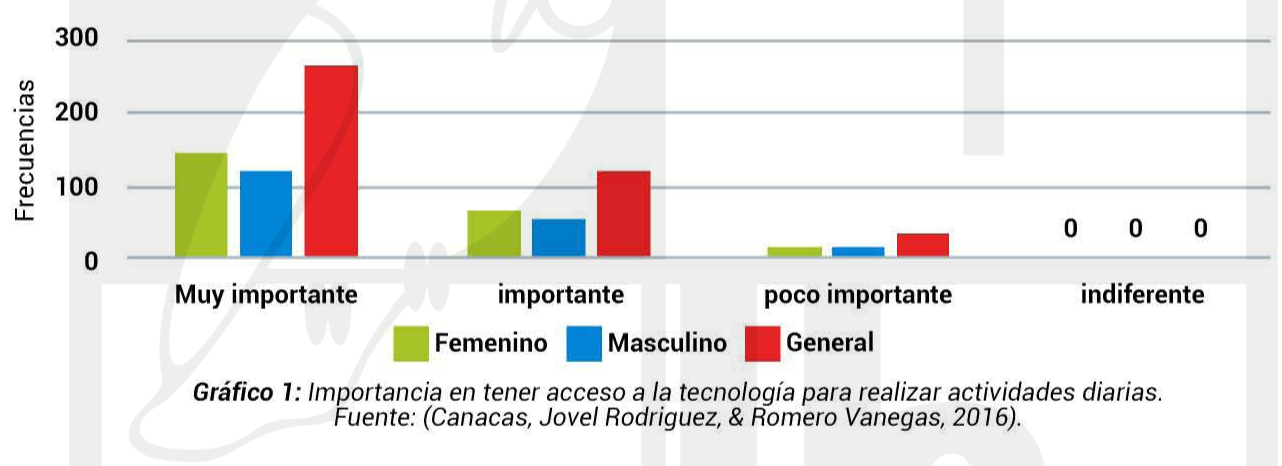

El $67 \%$ de los encuestados lo califica como muy importante, confirmando su necesidad de interaccion, no solo para comunicarse sino tambien como medio de informacion. Por lo tanto, para ellos poseer un dispositivo móvil se convierte en una necesidad vital.

Con un resultado afirmativo del 95\% (Ver grafico 2) los millennials le convierten a los dispositivos móviles en un producto de primera necesidad.
Hoy en día es necesario poseer un dispositivo móvil para los millennials salvadoreños (General).

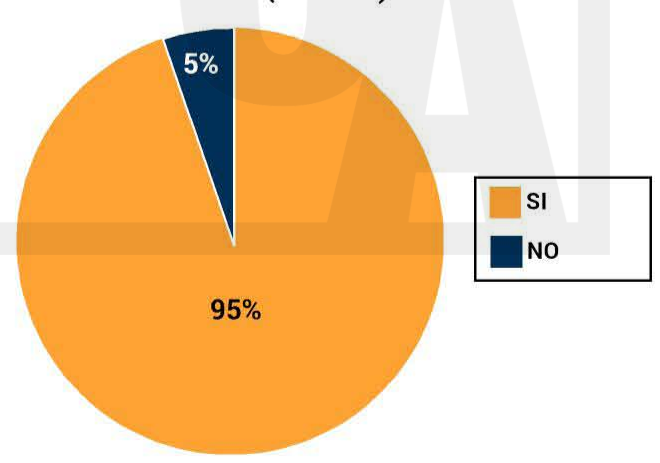

Gráfico 2: Necesidad de poseer un dispositivo móvil. Fuente: (Canacas, Jovel Rodriguez, \& Romero Vanegas, 2016) 
De acuerdo a la investigacion, el hablar por teléfono es una de las principales razones de porqué para ellos es importante poseer un dispositivo móvil , asi como una herramienta de trabajo que les permite conectarse al internet.

Tiempo que necesita estar conectado al internet o red social

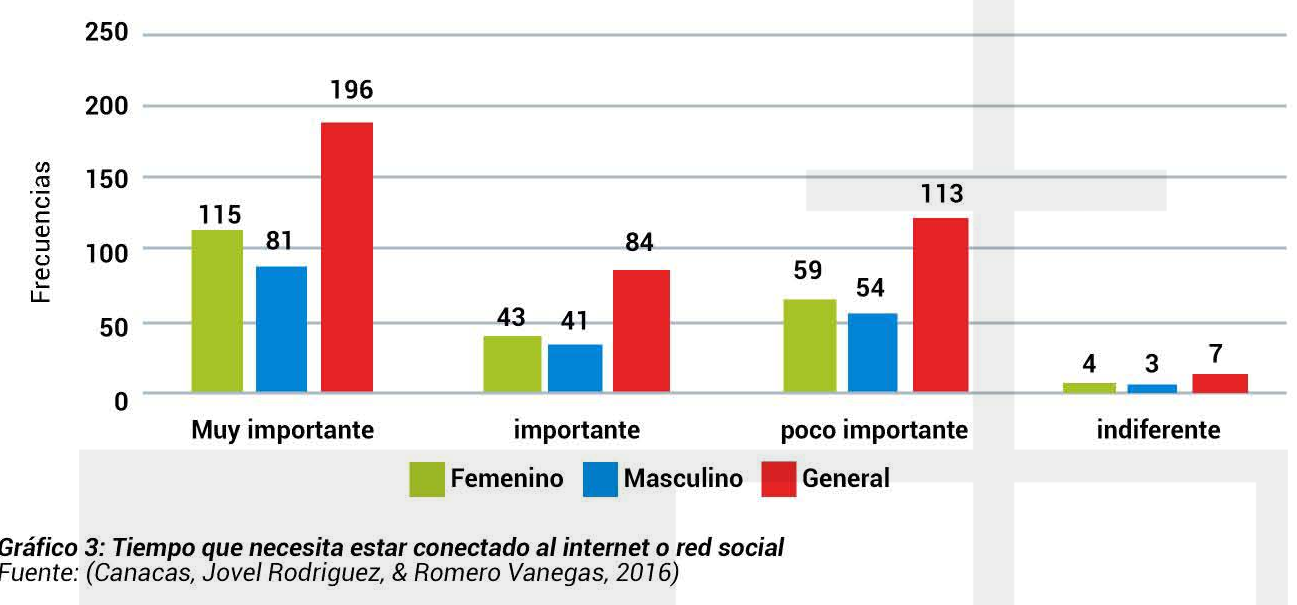

Practicamente el $49 \%$ de los millennials encuestados (Ver gráfico 3), necesitan estar conectados todo el dia y de éstos el $52 \%$ de las mujeres .

Por lo tanto, el medio de comunicación que utilizan los millennials para informarse sera la red social y el internet .Ver gráfico 4

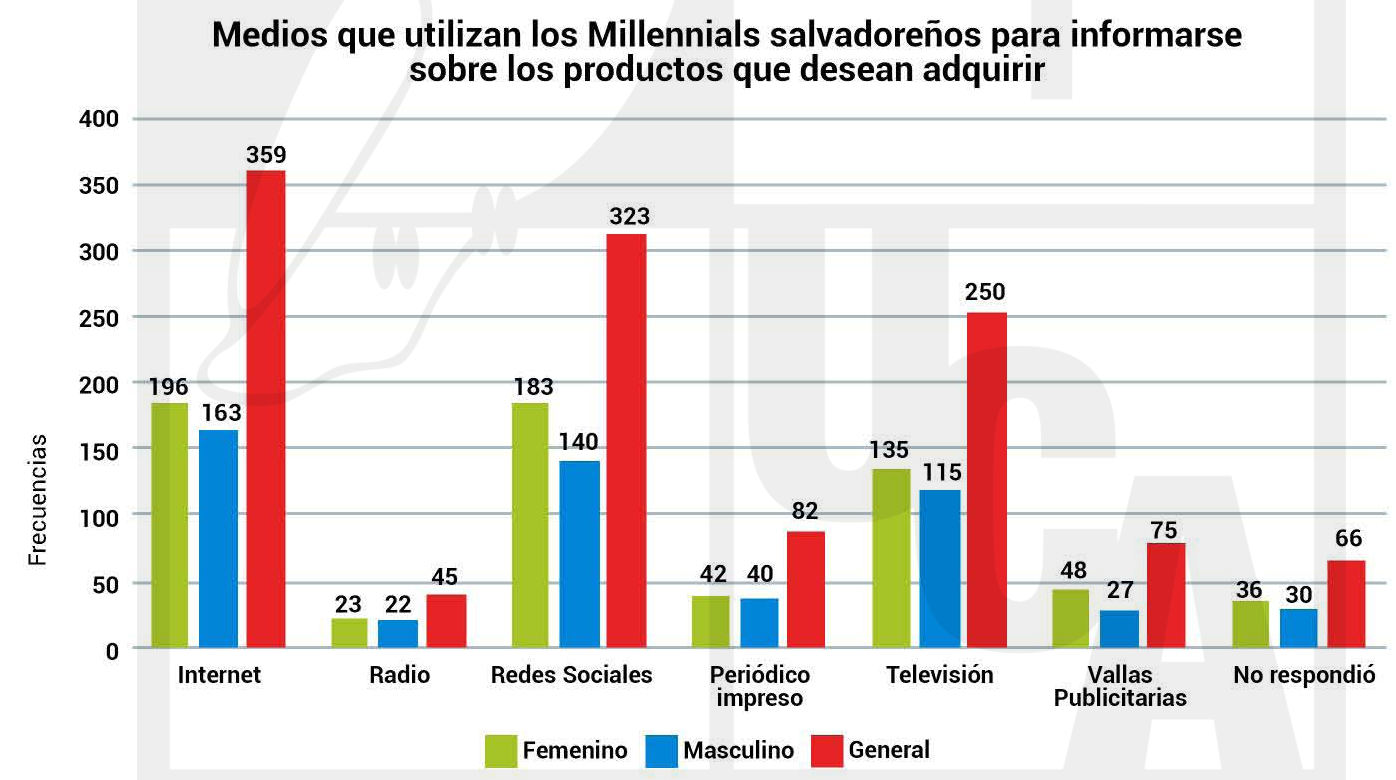

Gráfico 4: Medios que utilizan los Millennials salvadoreños para informarse sobre los productos que desean adquirir Fuente: (Canacas, Jovel Rodriguez, \& Romero Vanegas, 2016)

Es evidente, que los medios tradicionales como el periódico, la televisión, la radio y vallas publicitarias no son suficientes para impactar a los millennials esto implica un giro de las inversiones publicitarias hacia la red social y todos los medios digitales via internet. 


\section{Hábitos de consumo}

Con relación a los aspectos que influyen en sus decisiones de compra de los millennials, es evidente que este grupo es sensible al precio, se ven motivados más por ofertas o rebajas que pudieran ser promovidas via red social. Ellos eligen sus lugares de compra basándose en la oferta y el precio ofrecido por el establecimiento así como por su marca. A los jóvenes encuestados, se les pidió que eligieran los tres aspectos más importantes que influyen en su decisión de compra siendo el precio elegido por el $94 \%$ de los encuestados. Ver gráfico 5.

\section{Aspectos que influyen en la decisión de compra}

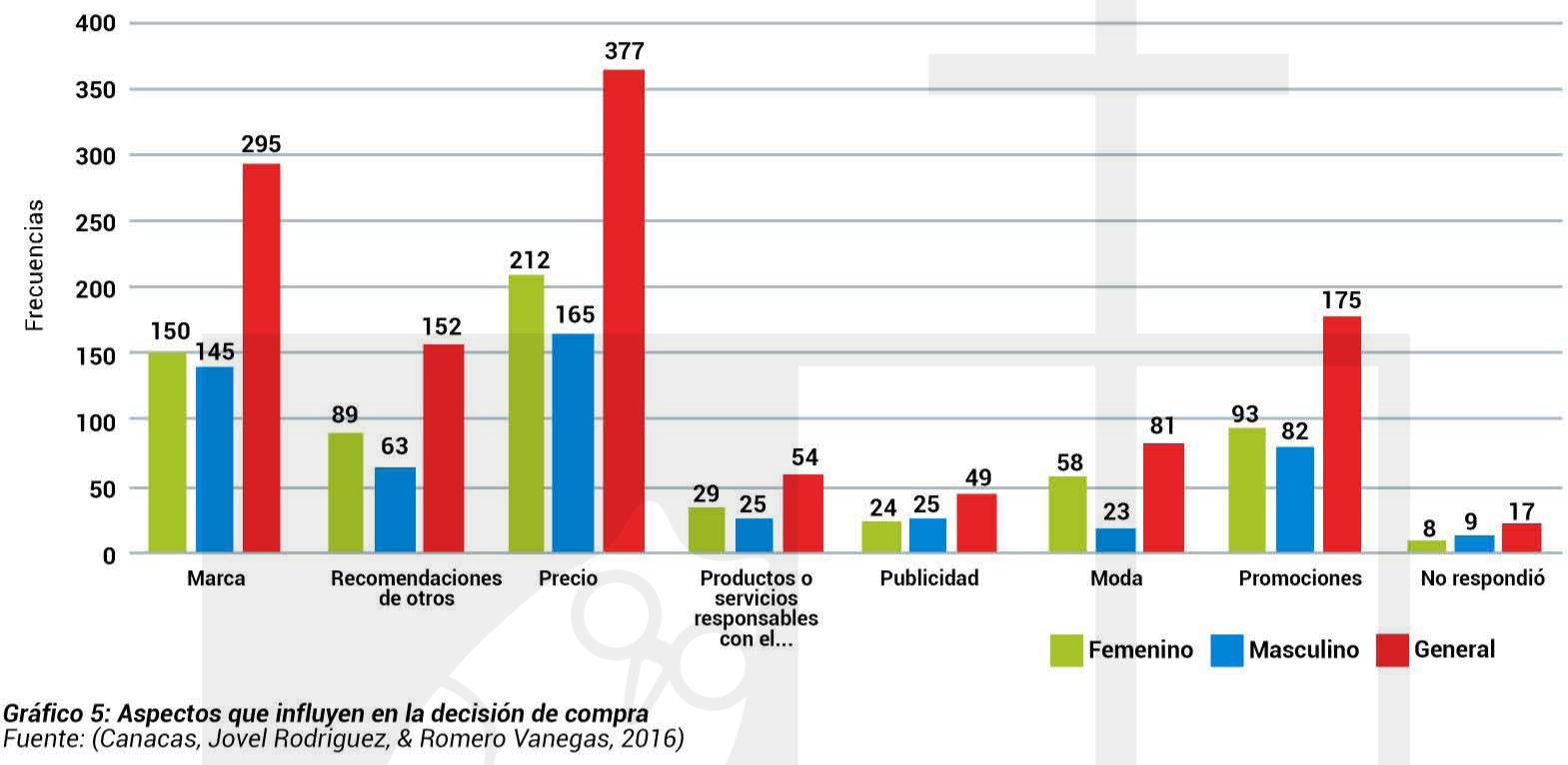

Aunque definitivamente el precio es el principal influenciador para los Millennials, ellos buscan obtener un buen beneficio o sea un valor por su dinero. De acuerdo a (Alsop, 2008) los Millennials están dispuestos a gastar, ya sea en articulos lujosos o en rebajas con tal que lo obtengan sea lo que ellos desean y esperan.

Asi las marcas deben de trabajar para mantenerlos leales proporcionándoles valores agregados a traves de la comunicación con éstos.

También se les pidió elegir entre los artículos o servicios que más les interesa adquirir, numerándolos del 1 al 5, siendo 1 el más importante y 5 el menos importante.Los resultados demuestran que la alimentación, la educación y el cuido personal son las más importantes, ya que fueron elegidos como primera opción (Ver gráfico 6). Esto es relevante para marcas de comida rápida y todo tipo de alimento con precios accesibles, y muestra un interés de los millennials en seguir educándose y capacitándose, así como también en el cuido y arreglo personal.

\section{Principales artículos o servicios que más interesan adquirir (1a. posición)}

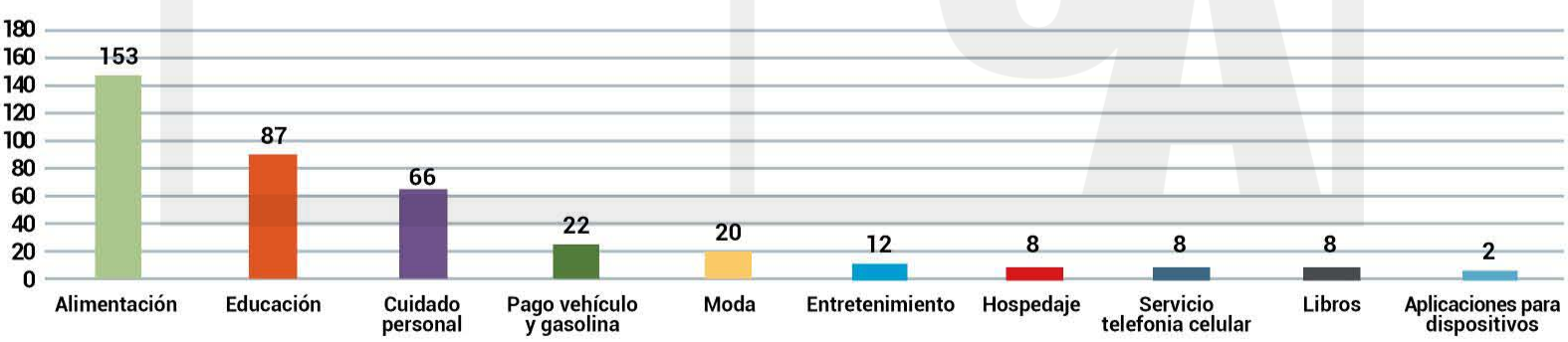

Gráfico 6: Primera opción en artículos de compra

Fuente: (Canacas, Jovel Rodriguez, \& Romero Vanegas, 2016) 
Cuando se trata de tomar una decisión de compra los Millennials son influenciados fuertemente por sus padres y amigos.

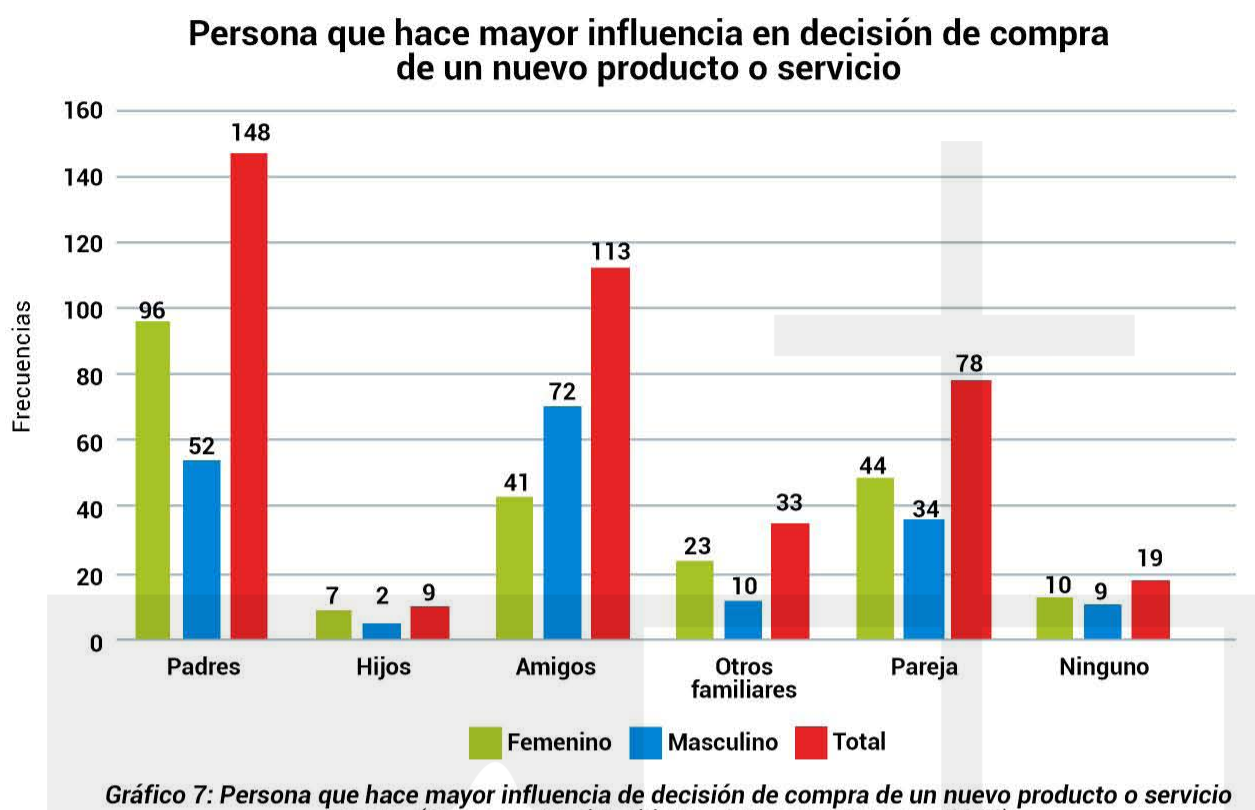

Gráfico 7: Persona que hace mayor influencia de decisión de compra de un nuevo producto o servicio Fuente: (Canacas, Jovel Rodriguez, \& Romero Vanegas, 2016)

El $37 \%$ de los Millennials salvadoreños son influenciados por sus padres y el $28 \%$ por sus amigos (ver gráfico 7 ). Esto indica que son personas para las que la opinión de sus seres más cercanos es de suma importancia, una característica de la juventud latinoamericana en general y que depende de la forma de crianza y del desarrollo del núcleo familiar.

\section{Intereses}

La principal motivación de los Millennials nacionales es formar una familia, manejar un negocio propio o tener un empleo y mantenerse saludable (ver gráfico 8). Lejos de parecer una generación despreocupada, sus intereses y motivaciones son serios y de acuerdo con la realidad, ya que ellos se enfrentan a una crisis económica que no les facilita el acceso al primer empleo y su desarrollo en el mundo laboral.
Los Millennials también son una generación más preparada que las anteriores, continúan estudiando, porque sienten la necesidad de seguirse desarrollando para convertirse en profesionales más competitivos. Según un estudio realizado por Manpower (Manpowergroup, 2016), un 80\% se mantienen en aprendizaje permanente y está dispuesto a invertir su propio tiempo y dinero para capacitarse más, también destaca que es esta generación quienes están trabajando durante periodos más largos y más duro que generaciones previas. El $79 \%$ afirma que lo hace durante más de 40 horas a la semana y más de una tercera parte por más de 50 horas. Un $42 \%$ tiene al mismo tiempo dos o más puestos de trabajo pagado.

\section{Principal motivación de los millennials salvadoreños}

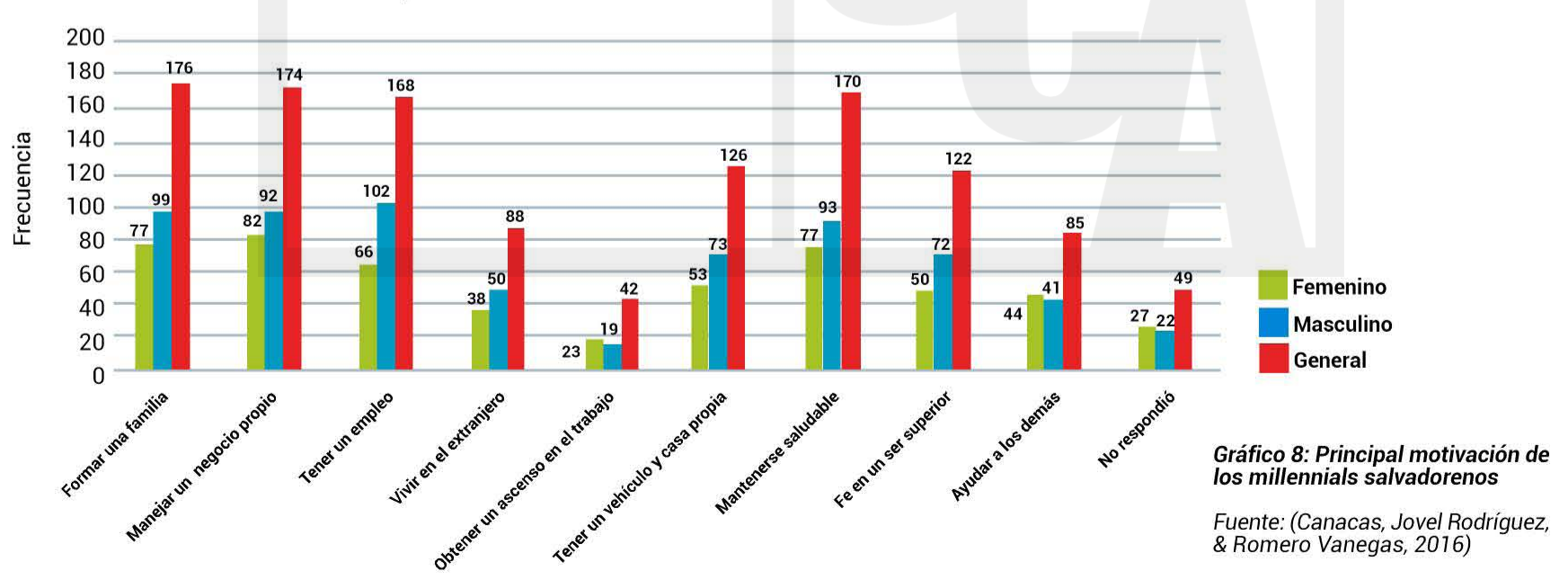


Estamos frente a una generación que depende para comunicarse de los dispositivos móviles, que le da una gran prioridad a la red social, que conserva todavía ciertas características conservadoras como formar una familia y el respeto por la opinión de sus padres y que por su edad necesitan ingresar al mundo laboral, ya sea con un empleo o con un negocio propio.

Hoy en día, las compañías están luchando por integrar a los Millennials junto con otras generaciones anteriores en el lugar de trabajo, más que todo con los baby boomers, que prácticamente ya van de retirada. Las empresas deberán aprender de los Millennials y su estilo de vida, porque quieran o no ellos representan la futura fuerza laboral.
En los Estados Unidos se realizó un estudio en el cual se determinó que el $85 \%$ de los gerentes de recursos humanos perciben que los Millennials se sienten con más derechos que otras generaciones. Sus mayores expectativas laborales son: salarios altos, horarios flexibles de trabajo, un ascenso en un año de trabajo y más vacaciones o tiempo personal. (Alsop, 2008).

Por tanto, las compañías deberán revisar sus procesos de contratación pero más que todo ofrecer verdaderas expectativas de mejoras laborales para mantenerlos fieles al puesto de trabajo.

\section{Conclusión}

Los Millennials se convierten en un reto para el marketing, ya que lo ideal para toda marca es tener estrategias que conquisten a la mayoría de sus clientes, pero si queremos conquistar a esta generación, debemos de modelar las estrategias enfocadas exclusivamente a ellos. Así que una táctica de mercadeo para todos los grupos generacionales se convierte en imposible con los Millennials, y definitivamente si para la empresa los Millennials constituyen su principal grupo objetivo, con más razón sus esfuerzos mercadológicos deberán ser dirigidos a ellos.

Por ejemplo, para las anteriores generaciones, sí es importante tener un dispositivo móvil para comunicarse, pero si funciona correctamente el que poseen, ¿por qué razón tendría que cambiarlo? Para los Millennials, la tecnología es importante y tienen que poseer la última tecnología a toda costa. Esto implica para las empresas una modernización de todos los sistemas tecnológicos disponibles, a fin de poder comunicarse con ellos. Y esto es una diferencia generacional muy fuerte, ya que los Millennials están más dispuestos a adoptar y aprender nuevas tecnologías que otras generaciones. $Y$ este deseo de aprender de nuevas tecnologías los ha llevado a convertirse a veces en los expertos en tecnología dentro de algunas empresas y les ha abierto oportunidades de trabajo.

Otro aspecto importante a revisar en Marketing es el mensaje a comunicar, tomando en cuenta su afinidad por la tecnología, el medio de comunicación a emplear es importante pero más la forma de comunicarnos con ellos. El vocabulario empleado es tan tecnológico como: "dale like", "manda un whatsapp", "¿hay Wi-Fi?", "¿ya tienes la App?", etc., que a veces se convierte en lenguaje extranjero para generaciones mayores. El lenguaje que se utiliza para conquistar a los Millennials deberá ser aquel que ellos entiendan a la perfección y que nos garantice su total atención.

Esta generación digital ama claramente la atención y la fama en el cyber espacio, es un grupo obsesionado por celebridades que creció viendo American Idol, y chismes de Internet. Los Millennials comparten los aspectos más mundanos y más sensacionales de sus vidas en redes sociales como Facebook, opinan en blogs y colocan videos personales en YouTube. (Alsop, 2008).

Si nos damos cuenta de la importancia de la opinión de sus amigos en sus decisiones de compra, el uso de influenciadores es una estrategia de marketing que con ellos puede funcionar y por ello muchas marcas lo usan en sus fan page, utilizando otros jóvenes que tengan esa capacidad de influencia. Además a los Millennials salvadoreños les encanta divertirse entre amigos, el 59.2\% de los encuestados seleccionó esta opción como una de las principales actividades en sus ratos libres, junto con hacer ejercicio (38.5\%) y visitar lugares al aire libre $(29.8 \%)$ (Canacas, Jovel Rodriguez, \& Romero Vanegas, 2016). Las marcas que logren capitalizar estos deseos de entretenimiento lograrán un acercamiento efectivo. En la estrategia de marca se deberán contemplar actividades que interesen a los Millennials y más que todo que puedan compartir con sus amigos. 
Su deseo de participar y compartir opiniones los convierte en grandes asesores de las marcas, ya que ellos están dispuestos a comentar, generar opiniones y ser co-creadores de estrategias y acciones, actividades que hace unos años eran de alto costo para las empresas. Ahora se convierten fácilmente en una fuente de información económica y en tiempo real, gracias a esta generación y su interacción con la red social.

En El Salvador, las compras por Internet no son muy frecuentes ni aún por los Millennials. De acuerdo al estudio, el $23 \%$ utiliza con frecuencia el internet para realizar compras (Canacas, Jovel Rodriguez, \& Romero Vanegas, 2016) esto debido a la falta de confianza en el sistema de compras on line nacional. Sin embargo, las compras on-line llevan tendencia a crecimiento empujadas por esta generación, que cada vez prefiere el trato virtual al personalizado y que sabe que puede conseguir cualquier cosa, no importa que se encuentre del otro lado del mundo.

De esta manera, los Millennials se han convertido en una generación de la gratificación inmediata, acostumbrados a obtener información rápida, y prácticamente cualquier cosa sin mayor esfuerzo; piensan que todo lo consiguen con el click, llegando a creer algunas veces que el mundo real es de esta manera. Se sienten frustrados cuando tienen que mantener una relación o un trabajo, los cuales toman tiempo y requieren de mucha madurez y paciencia. Sin embargo, el lado positivo y que les diferencia de las generaciones anteriores, es que están más dispuestos a colaborar con otros, compartir opiniones, ofrecer su punto de vista, libres de expresar sentimientos y emociones; $y$ apasionados de la tecnología, han cambiado por siempre la manera de realizar el marketing.

\section{Bibliografía:}

Alsop, R. (2008). he Trophy Kids Grow Up : How the Millennial Generation Is Shaking Up the Workplace. San Francisco, USA: Jossey-Bass.

Canacas, I. B., Jovel Rodriguez, D. E., \& Romero Vanegas, J. A. (Octubre de 2016). Estudio sobre los intereses, necesidades y habitos de consumo de los millennials Salvadoreños. San Salvador, El Salvador: Universidad Centroamericana Jose Simeon Cañas.

Forbs. (2016 de Noviembre de 2016). Forbs. Recuperado el 14 de junio de 2016, de Forbs: http://www.forbes.com.mx/7-cosas-que-debes-saber-sobre-la-generacion-z/\#gs.jdadN00

Forbs. (22 de Diciembre de 2014). Forbs. Recuperado el 14 de junio de 2016, de Forbs: http://www.forbes.com.mx/6-rasgos-clave-de-los-millennials-los-nuevos-consumidores/\#gs.I6lHi_k

Giralt, M. (2009). uca.edu.sv. Recuperado el 2 de agosto de 2016, de uca.edu.sv: http://www.uca.edu.sv/publica/iudop/libros/LIBROINFORMEJUVENTUDIUDOP09.pdf

Jeff, F. (2013). En Marketing to millennials. New York: Amacon.

Manpowergroup. (2016). Manpowergroup. Recuperado el 10 de junio de 2016, de Manpowergroup: http://www.manpowergroup.com.mx/uploads/estudios/Millennials_Vision2020.pdf

Sim Pritam, R. S. (2012). millennials and the workplace. New Delhi: sage Publications.

Winograud Morley, H. M. (2011). En Millenial Momentum. New York: Rutgers University Press. 